\title{
CALORIMETRIC RESISTANCE THERMOMETERS AND THE TRANSITION TEMPERATURE OF SODIUM SULPHATE.
}

By H. C. Dickinson and E. F. Mueller.

\section{CALORIMETRIC RESISTANCE THERMOMETERS.}

\section{INTRODUCTORY.}

Of the methods in use for temperature measurement, the variation in resistance of metallic wires affords probably the most accurate means of obtaining differences of temperature over a limited range. When the resistance material is a pure metal, resistance is in most cases a simple function of temperature. The metal most generally used has been platinum, because of its high specific resistance, high melting point, and freedom from oxidation. The platinum resistance thermometer has been developed and carefully studied by a number of able experimenters. ${ }^{1}$

The form of resistance thermometer most generally used consists of a coil of platinum wire wound on an open frame of nica, connected to heavy platinum leads and surrounded by a tube of glass or porcelain from 1.0 to $1.6 \mathrm{~cm}$ in diameter. When intended for use with a potentiometer, four leads are used - two current leads and two potential leads. If for use with a Wheatstone bridge, the coil is connected to one pair of leads, and another similar pair in the form of a simple loop is placed beside them and connected in the adjacent arm of the bridge to compensate for varying depth of immersion.

${ }^{1}$ Callender, Phil. Trans. A, 17S, p. I6I; ISS7. Callender and Griffiths, Phil. Trans. A, 182, p. II9; ISgr. Harker and Chappuis, Phil. Trans. A, 194, p. 37; I 900. Harker, Fhil. Trans. A, 203, p. 343; 1904. Dewar, Proc. Roy. Soc., 73, p. 244 ; 1904. 
The present investigation has to do with the adaptation of the resistance thermometer to calorimetric and other uses for which the ordinary form is not suited. For use in a calorimeter, or where temperatures are changing rapidly, a resistance thermometer must satisfy some special conditions: (a) It must quickly assume the temperature of its surroundings, so that its indications may give the true temperature at the time of observation; $(b)$ it must have small heat capacity and must conduct little heat away from the bath in which it is immersed; $(c)$ thermo-electromotive forces must be avoided so far as possible; $(d)$ the resistance should be relatively high; $(e)$ conduction of heat by the leads, affecting the temperature of the resistance coil, must be avoided; $(f)$ as in any resistance thermometer, the leads must be so adjusted that the indications are independent of the depth of immersion, i. e., the resistance of the compensating leads must equal that of the coil leads when a bridge method is used; $(g)$ insulation resistance must be high to avoid leakage.

In some special cases it has been possible to use bare platinum wires without any protecting sheath-as for the measurement of the temperature of gases under certain conditions-but for most purposes it is necessary to provide. some protection. To provide such protection and still allow rapid equalization of temperature requires some special device. Evidently the best results will be obtained by the use of a thin sheath of metal with a layer of the thinnest possible insulating material between it and the resistance coil. Jaeger and Steinwehr ${ }^{2}$ have described a resistance thermometer made after this plan which they have used in several investigations. The thermometer described below has been developed along somewhat different lines. It was desired to build an instrument having the resistance coil in small compass, so that it could be used to determine the temperature, at a definite point, of a liquid flowing in a tube. As it is important to liave a large external surface, the use of a flat coil and thin flat sheath suggested itself. To get a moderately high resistance, the use of very fine wire was tried, and, after a number of preliminary experiments, a wire of about $0.02 \mathrm{~nm}$ diameter was found to serve the purpose.

${ }^{2}$ Jaeger und Steinwehr, Zs. für Instrk., 26, p. 237; 1906. 


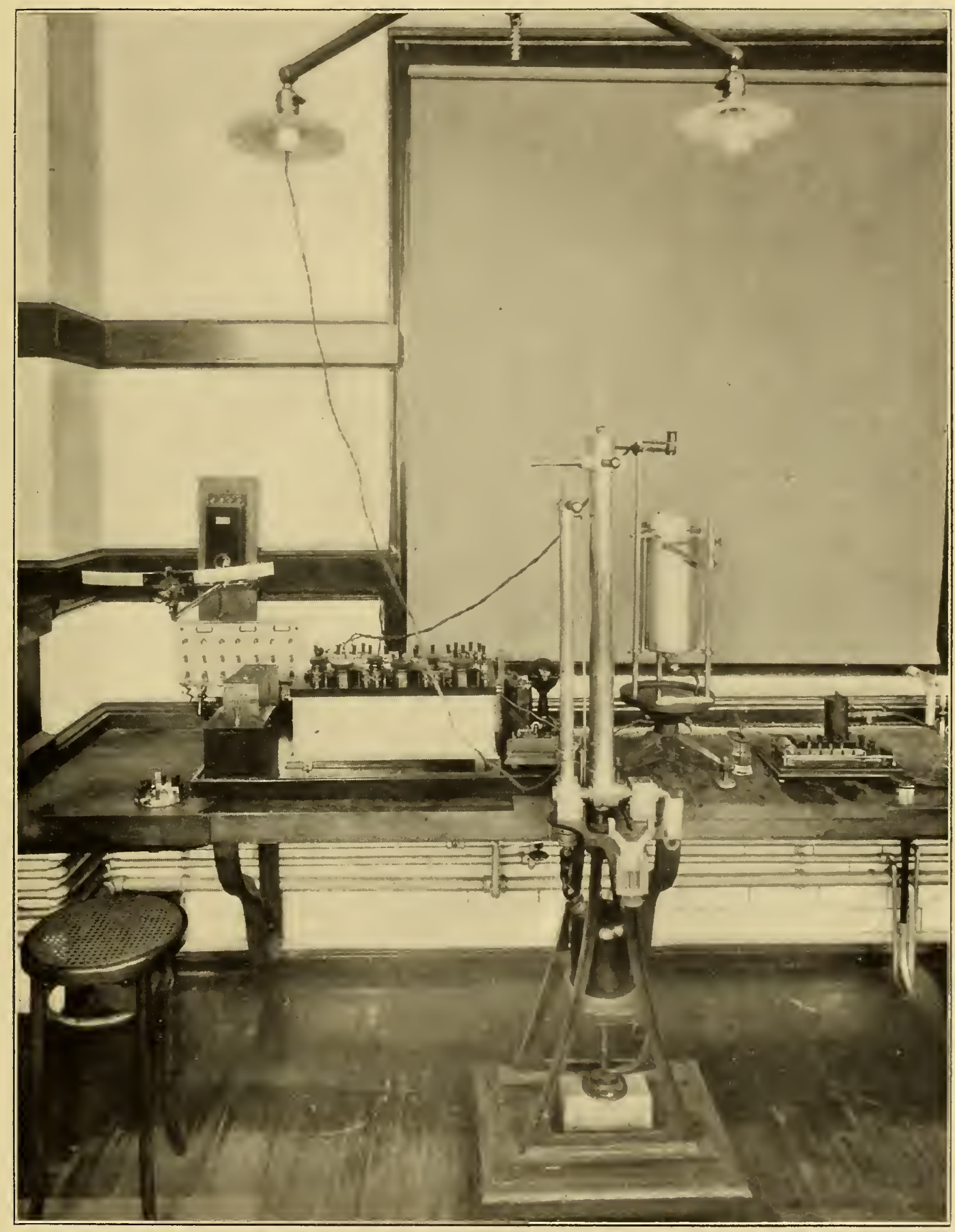

Fig. 1.-Apparatus used in Fundamental Interval Determinations. 


\section{DESCRIPTION OF THE THERMOMETERS.}

The accompanying cut (Fig. 2) shows the construction finally adopted. The four leads $(L)$ are of thin copper strip abont $4 \mathrm{~mm}$ wide and $0.12 \mathrm{~mm}$ thick. To each of these is fused a short piece $(T)$ of o.I mm platinum wire about ro mm long. The leads are then laid side by side, separated by thin mica strips $(M)$, and one pair is connected to the ends of a coil $(C)$ of about Io chn of $0.02-111 m$ platinum wire wound in a flat coil on one of the mica strips; the other pair of leads are connected by fusing together the ends of the short platinum terminals. ${ }^{3}$ These parts are shown separated in Fig. 2 b.

The use of these thin platinum terminals on both the main and the compensating leads was found to be necessary to compensate for the conduction of heat by the copper leads which would affect the temperature of the resistance coil. After the adoption of this method of connecting the coil to the copper leads, no further trouble was experienced. The leads and coil thus prepared were enclosed in a flat sheath (S) of thin copper (0.12 mm thick) and insulated from it by thin mica. This sheath was soldered along the side and copper-plated to strengthen it somewhat and then gold-plated to protect from oxidation. The sheath when finished was about $7 \mathrm{~mm}$ wide and I mm thick, somewhat thinner at the coil. Two thermometers thus constructed were sealed into heads $(\mathrm{H})$, of fiber as shown in Fig. 2 a, but it was found that moisture entered these heads and the insulation between leads and outer sheath was impaired. To avoid this trouble, heads of hard rubber were substituted and the covers (D), containing drying salt were also added. These covers open into $\mathrm{H}$ through the small glass tube $(\mathrm{G})$.

The thermometers here described fulfill the requirements outlined

\footnotetext{
${ }^{3}$ In making up these thermometers it was found impracticable to wind the coils after fusing to the leads, and to overcome the difficulty of fusing wires so fine as 0.02 $\mathrm{mm}$ in somewhat inaccessible positions an arc was used. The arc was formed between a small graphite pencil and one of the terminals to be fused, when the other terminal was brought up and the two connected. After a little practice this could be done quickly and neatly. This same method has since been used to advantage in fusing together wires of different materials and sizes. The platinum terminals also were fused to the copper leads by the same method. The fusing of copper wires is more easily effected when borax is used as a flux. It is necessary to regulate both the voltage and the resistance in series with the arc for different sizes of wire.
} 


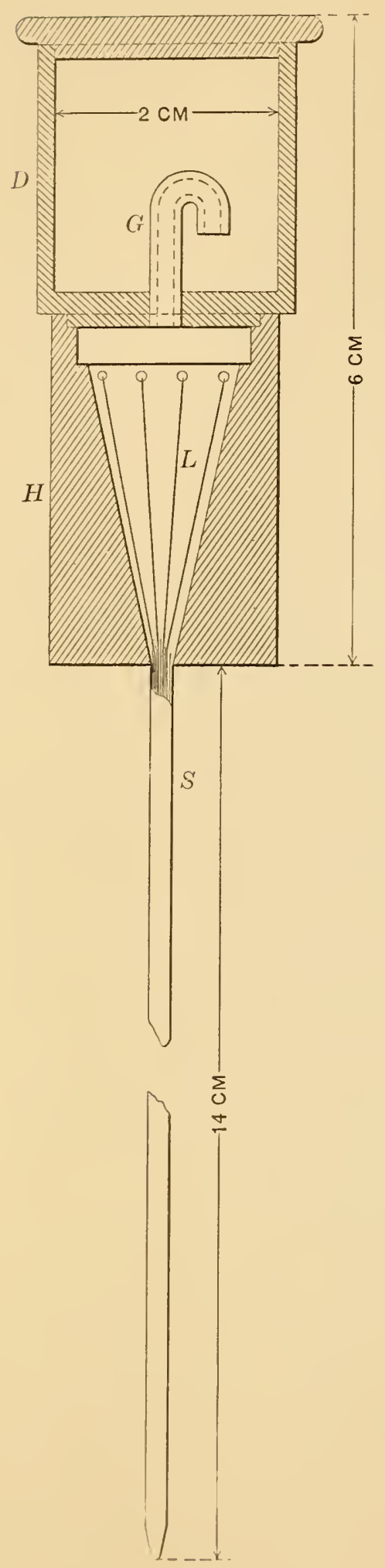

(a)

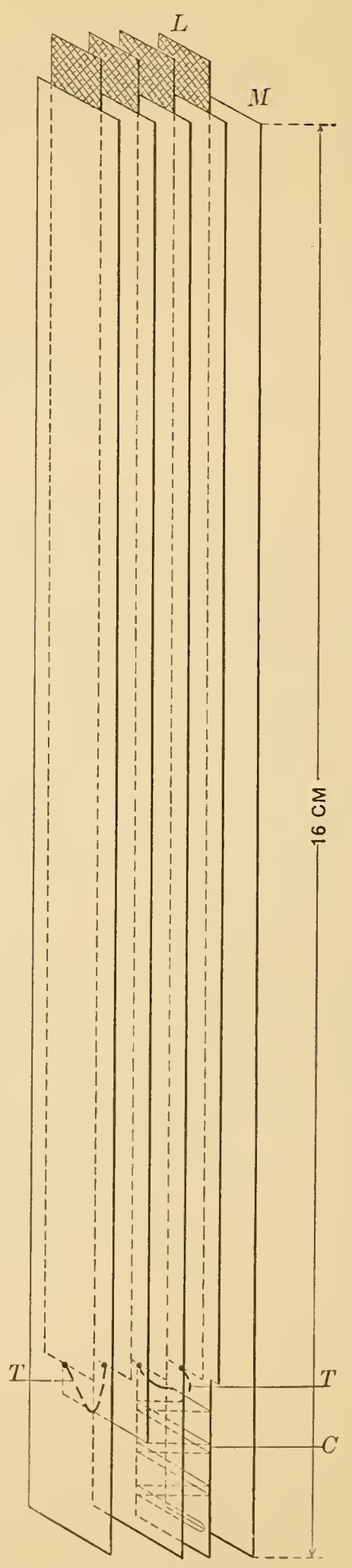

(b)

Fig. 2.-Diagram showing construction of thermometer. 
above in a very satisfactory manner. ( $(\alpha)$ When inmersed in ice or stean they assume the temperature to within 0 :oo i in about three seconds. This time constant has not, however, been very carefully determined, as the period of the galvanometer is much longer than the time lag of the thermometer. (b) The water equivalent of the thermometers, exclusive of the heads which are not immersed, is less than I gram. The heat condnctivity of the leads is small, and as its effect can be eliminated in most cases, no determination has been made. (c) The junctions of the copper leads with the platinum coil are made within the thermometer sheath and are separated from each other by only a thin layer of mica, so that thermo-electromotive forces from these junctions are extremely small. The small thermo-electromotive forces observed seem to come entirely from the external circuit and are never troublesome. (d) The resistance of these thermometers is approximately 30 ohms in ice and 40 ohms in steam, so that a change of O.I ohm corresponds to $\mathrm{I}^{\circ}$ change in temperature. (e) The effect of heat conductivity of the leads in changing the temperature of the platinum coil has been so far avoided by the device described above (Terminals (T), Fig. 2) that no effect is noticeable when the immersion of the sheath is as much as $5 \mathrm{~cm}$. $(f)$ The resistance is made independent of the temperature of the exposed portion of the sheath by the use of compensating leads. $(g)$ After adding the drying capsules to the heads of the thermometers the insulation resistance was found to be over Ioo megohms, so that errors due to leakage are negligible.

In reference to the resistance coil of $0.02-1 m m$ wire it may be said that considerable care was exercised in winding and annealing. The wire was first glowed by passing a current through it for some minutes, heating to about $\mathrm{I}, \mathrm{OOO}^{\circ}$; then, after winding on the mica strip, the process was repeated at a somewhat lower temperature, and finally, after the sheath was put on, the whole was heated to abont $400^{\circ}$ in an oven before soldering up.

The thermometers described by Jaeger and Steinwehr ${ }^{4}$ showed a depression of $R_{0}$ (the resistance in melting ice) after heating to $100^{\circ}$, corresponding to abont $\mathrm{O}$. I or nearly the same as is slown by a good mercury-in-glass thermoneter. With this fact in mind several 
special experiments were made to see if the same effect were present in this type of instrument, but the results failed to show the slightest trace of a change after heating.

A second pair of thermometers similar to those described was made later and showed some irregularities which, however, were soon traced to mechanical strain of the wire, and when the cases were slightly opened out around the bulb these irregularities disappeared.

\section{RESISTANCE MEASUREMENTS.}

Measurements of resistance were made by the Wheatstone bridge method using a bridge (Fig. I) constructed for the Bureau of Standards three years ago especially for resistance thermometry. This bridge, shown diagrammatically in Fig. 3, has an adjustable resistance of IIO ohms-the lowest coils being O.OI ohm. In place of a bridge wire, three slides are used giving steps of $0.00 \mathrm{I}, 0.000 \mathrm{I}$, and 0.0000 I ohm, respectively. The slides each have ten steps and consist of a series of coils shunted over a portion of the resistance in the main bridge arm. This arrangement avoids the uncertainty of a bridge wire calibration since only moderate accuracy is required in adjusting the shunt coils, and in addition makes the bridge direct reading. Mercury contact links are used for all connections in the main circuit and their resistance which is about 0.0000:6 ohm per link, has proved to be constant to better than IO\%. Ratio coils of IO, IOO, I,OOO, and I0,000 ohins are provided, but the I,O0O-ohm coils were used throughout this investigation. The ratio coils can be interchanged by moving two links. The coils are immersed in oil and the temperature is kept constant at $30^{\circ}$ by means of a thermostat and stirrer. Reversing keys for battery and galvanometer and an Ayrton-Mather universal galvanometer shunt are provided. A Griffiths thermo-electric key immersed in oil was used so that the galvanometer circuit was always closed except at the instant of making the battery circuit.

The bridge has been calibrated four times with great care at intervals during the progress of the work, and all measurenents are corrected to these calibrations. Throughont the present investigation the measurements were made with an electromotive force of 2.6 volts. With this arrangement the current in the thermometers was 
kept nearly constant at 0.0025 ampere. Experiments showed that this current raised the temperature of the thermometer coils o:oro5 when in ice and o:orIo when in steam. It thus appears that this heating effect is constant within the limits of observational error, and as the calibration and all measurements were made under the same conditions no correction need be applied.

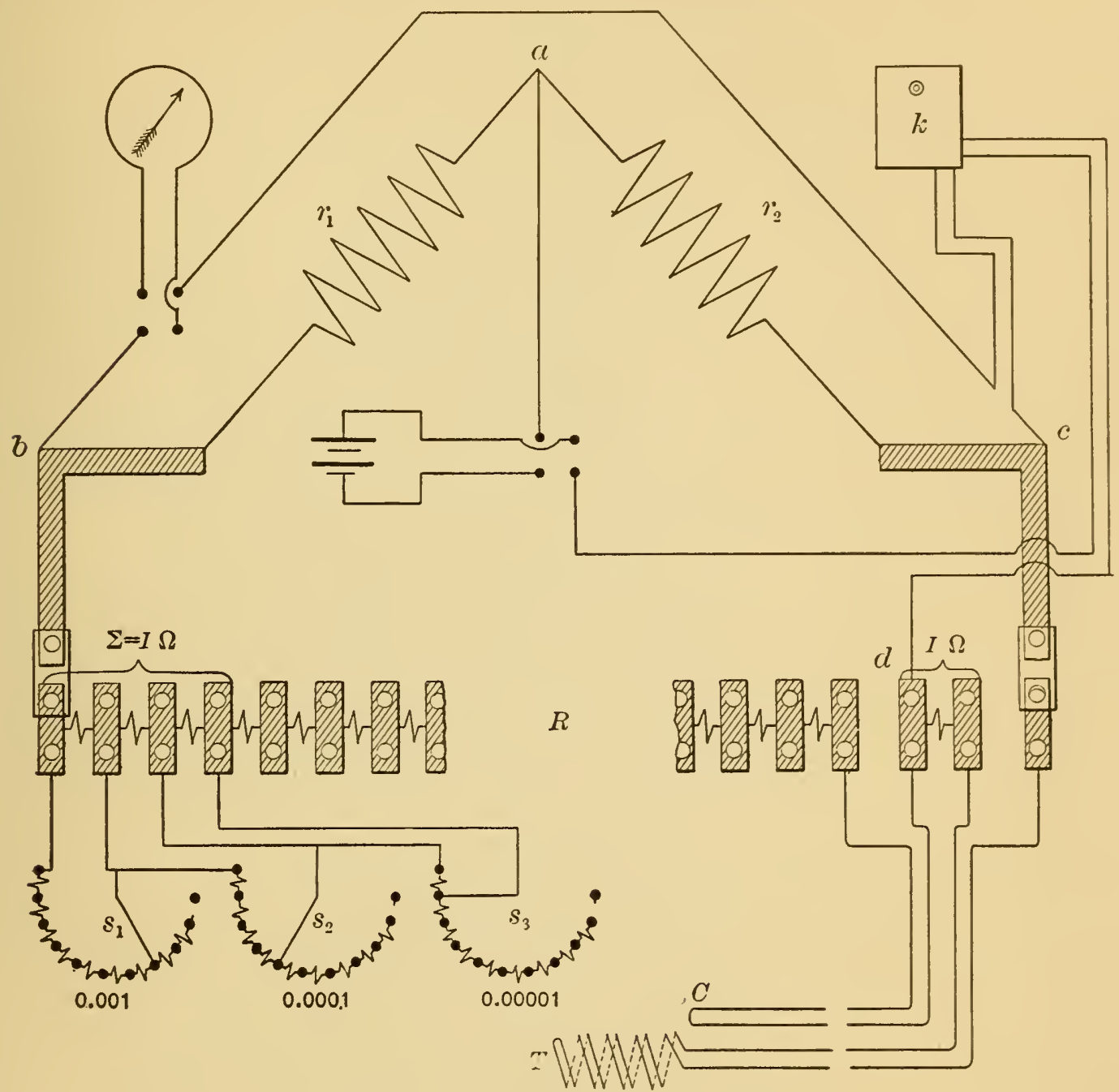

Fig. 3.-Diagrammatic sketch of bridge.

The galvanometer used was of the Broca type, with vertical magnets, having their consequent poles at the center of the coils, and was adjusted to a sensibility of about 600 megohms. With the scale placed at $50-\mathrm{cm}$ distance, this gave a deflection of $\mathrm{I} \mathrm{mm}$ for a change of $0.000 \mathrm{I}$ ohm in the resistance to be measured, or, in other words, I mm deflection per o:oor. 


\section{CALIBRATION OF THE THERMOMETERS.}

A platinum temperature scale may be defined in terms of resistance. If $R_{0}$ is the resistance in melting ice and $R_{100}$ the resistance in steam, under standard conditions, and $R_{\mathrm{t}}$ any observed resistance, then the corresponding platinum temperature is defined thus:

$$
p t=\frac{R_{\mathrm{t}}-R_{0}}{R_{100}-R_{0}} \times \text { I00. }
$$

Callendar has given the relation between temperature " $t$ " on the gas scale and " $p t$ " as defined above in the form $t-p t=\delta(t /$ IOO $-\mathrm{I}) t /$ roo where $\delta$ is a constant. This relation has been shown to hold within the limits of accuracy at present attained in gas thermometry between $-100^{\circ}$ and $\mathrm{I}, 100^{\circ}$ when $\delta$ is determined by observation at $0^{\circ}, \mathrm{IOO}^{\circ}$, and the boiling point of sulphur $\left(444^{\circ} \cdot 7\right)$.

The three constants of the resistance thermometer $\left(R_{0}, R_{100}, \delta\right)$, are fixed by measuring the resistance in melting ice, in steam, and at one other temperature which is known in terms of the gas scale.

Determination of $\mathbf{R}_{0}$ and $\mathbf{R}_{100}$. - In the course of six months the resistance $R_{0}$ of the thermometers changed slightly, the one by 0.0006 and the other by $0.00 \mathrm{I} \mathrm{ohm} \mathrm{while} \mathrm{small} \mathrm{variations} \mathrm{of} 0.000 \mathrm{I}$ or 0.0002 ohm (o:oor or $0: 002)$ were observed from day to day. These small irregularities are near the limits of accuracy of measurement and can not be definitely ascribed to any one cause, while the secular change may be due to varying state of strain in the wire, or more probably to changes in the leads and terminals. The changes in the bridge itself have been much larger than the changes in the thermometers. It should be noted that to maintain $R_{0}$ constant to 0 . oo I resistances must remain constant to I in 300,000 , but for the same constancy of temperature indication the coils representing the difference $R_{100}-R_{0}$ need remain constant to only I in I00,000. In the present instance nearly all the change observed was in a 20-ohm coil which was always in circuit, and therefore did not affect the value of $R_{100}-R_{0}$ or of $R_{\mathrm{t}}-R_{0}$. For these reasons it is evident that the best results should be obtained from a series of independent determinations of $R_{100}-R_{0}$ referring measurements at other temperatures to the $R_{0}$ determined at the time. This method was followed througliout the present work. The results of the series of inde- 
pendent determinations of the $R_{100}-R_{0}$ are given in the following table.

TABLE I.

Values of $R_{100}-R_{0}$.

\begin{tabular}{|c|c|c|c|c|}
\hline \multirow{2}{*}{ Date } & \multicolumn{2}{|c|}{ Thermometer $\mathrm{A}$} & \multicolumn{2}{|c|}{ Thermometer B } \\
\hline & $\mathbf{R}_{1)}$ & $\mathbf{R}_{1+x \mid}-\mathbf{R}_{1,}$ & $R_{11}$ & $\mathbf{R}_{1, x}-\mathbf{R}_{1,}$ \\
\hline $10-6-06$ & 29.00548 & $\begin{array}{l}9.75060 \\
9.75068\end{array}$ & 28.94158 & $\begin{array}{l}9.76746 \\
9.76755\end{array}$ \\
\hline $10-8-06$ & 29.00498 & $\begin{array}{l}9.75079 \\
9.75097\end{array}$ & 29.94128 & $\begin{array}{l}9.76777 \\
9.76777\end{array}$ \\
\hline $10-12-06$ & 29.00530 & $\begin{array}{l}9.75055 \\
9.75055\end{array}$ & 28.94160 & $\begin{array}{l}9.76747 \\
9.76709\end{array}$ \\
\hline $10-18-06$ & 29.00570 & $\begin{array}{l}9.75063 \\
9.75062\end{array}$ & 28.94202 & $\begin{array}{l}9.76720 \\
9.76720\end{array}$ \\
\hline $1-18-07$ & 29.00579 & $\begin{array}{l}9.75091 \\
9.75062 \\
9.75019\end{array}$ & 28.94230 & $\begin{array}{l}9.76717 \\
9.76728\end{array}$ \\
\hline $2-27-07$ & 29.00603 & $\begin{array}{l}9.75111 \\
9.75115\end{array}$ & 28.94260 & $\begin{array}{l}9.76791 \\
9.76800\end{array}$ \\
\hline & Mean & $\begin{array}{r}9.75072 \\
+\quad .00005\end{array}$ & & $\begin{array}{r}9.76749 \\
+\quad .00006\end{array}$ \\
\hline
\end{tabular}

[Note.-July, 1907. After a new calibration of the bridge $R_{0}$ was found to be 29.00570 and 28.94200 for A and B, respectively, indicating that the changes in the thermometers have been less than I in IOO,OOO.]

The apparatus used for the determination of ice and steam points is of the International Bureau form (Fig. I). Pressures were read on a Fuess standard barometer. All of this apparatus, as well as the mercurial thermometers and comparator subsequently referred to, and the methods and precautions observed in their use, are fully described in another paper. ${ }^{5}$

Determination of $\delta$. - As has been stated, the $\delta$ of the Callendar formula may be fixed by observing the resistance at a third known temperature. To determine its most probable value in the interval $\mathrm{O}^{\circ}$ to $\mathrm{IOO}^{\circ}$, the platinum thermometers were compared at several points witl a number of primary standard mercurial thermometers. It is evident that comparisons at temperatures near the fixed points 
where $t-p t$ is small, are of little value in the determination of $\delta$, so that observations are restricted to the middle part of the range $o^{\circ}$ to $100^{\circ}$. Further, in the use of mercurial thermometers it is advisable to select points at which the calibration corrections have been most accurately determined. For these reasons the points $30^{\circ}, 40^{\circ}$, $50^{\circ}, 60^{\circ}$, and $70^{\circ}$ were chosen.

The thermometers used at $30^{\circ}, 40^{\circ}$, and $50^{\circ}$ were Tonnelots Nos. $4332,4334,4335$, and 4336; and at $60^{\circ}$ and $70^{\circ}$ Baudins Nos. I6or6, I60I 7 , I6018, and I5962. Since all of these had been included in the intercomparisons by Waidner and Dickinson they give in effect the mean scale of twelve thermometers at $30^{\circ}$ and $40^{\circ}$, the mean of sixteen at $50^{\circ}$, and the mean of seven at $60^{\circ}$ and $70^{\circ}$.

The mercurial thermometers were mounted on the holder and the platinum thermometer was inserted through the cover of the comparator. ${ }^{6}$ With this arrangement the platinum thermometer was about $50 \mathrm{~cm}$ above the bulbs of the nercurial thermometers. The complete absence of irregular variations in the reading of the resistance thermometers shows that there were no local variations in tentperature in the comparator, so that any possible difference between the platinum and mercurial thermometers must have been constant. It may readily be shown that any such difference must be of negligible importance. ${ }^{7}$

Observations. - A whole day was required for the comparison at each temperature. The observations were carried out in the following order: $(a)$ The resistance of the platinum thermometers was measured in ice, in steam, and again in ice, giving $R_{0}$ and $R_{100}-R_{0}$;

${ }^{6}$ Waidner and Dickinson, loc. cit., note 5 .

${ }^{7}$ At $70^{\circ}$, the highest temperature used in these experiments, 300 watts were required to maintain the temperature constant. The loss of heat from the water was, therefore, 71.4 calories per second. The surface from which heat could be lost by the water between the bulbs of the mercurial and platinum thermometers was less than one-twentieth of the total. This surface was at least as well protected as the average, so that if the loss per unit surface be assumed uniform, this portion should lose 3.6 calories. The water contained in this space was about 5,000 grams, so that its temperature should fall $0: 0007$ per second. The time required for a given portion of water to pass from the bulbs of the inercurial thermometers to the platinum thermometer was less than one second. The largest difference of temperature, therefore, was probably less than $0: 0007$. The time lag of the mercurial thermometers as compared with the platinum thermometers introduces another error of about the same magnitude and opposite sign. 
(b) in the meantime the temperature of the four mercurial thermometers in the comparator had been brought to the comparison point and two ice-point determinations were made for each, both estimates and nicrometer settings being made by each observer (a similar series of ice-point determinations was made after the comparison); (c) the mercurial and platinum thermometers were put in position in the comparator and the readings taken. Table II contains half the readings in the comparison of thermometer $\mathrm{A}$ at $40^{\circ}$ and shows the procedure. Series one and four are micrometer observations and series two and three are estimates. The numbers in brackets in columns marked $(t)$ are estimated readings used to check micrometer observations. The corrections to the reading of each thermometer are given at the bottom of the respective columns. The sixth and seventh columns contain the bridge readings and corresponding values of $R_{t}$. The last column contains $p t, t$, and the values of $t-p t$ and $\delta$ for each series.

A single series consisting of sixteen readings on the mercurial thermometers and eight resistance measurements took about five minutes, and the temperature was so controlled that a rise of from 0 :o I to $0: 03$ was secured.

The values of $t-p t$ deduced from the observations, and the corresponding values of $\delta$ are given in Table III. The largest residual in terms of temperature is 0.002 . In the course of other work the platinum thermometers have been compared with two mercurial standards at $5^{\circ}, 15^{\circ}$, and $22^{\circ}$. Using the value of $\delta$ from this calibration the largest difference observed was $0: 005$, which is abont the probable error of the mercurial thermometers. It appears from the results obtained that $\delta$ is constant between $0^{\circ}$ and $100^{\circ}$ to within the limits of observational errors of mercurial thermometers and that these platinum thermometers calibrated in this way will serve to determine temperatures on the International Hydrogen Scale to abont 0.002 . For calorimetric work, where the temperature difference is only a few degrees, the interval defined by these thermometers may be taken as representing the interval on the hydrogen scale to a much higher order of accuracy.

$3608-07-8$ 


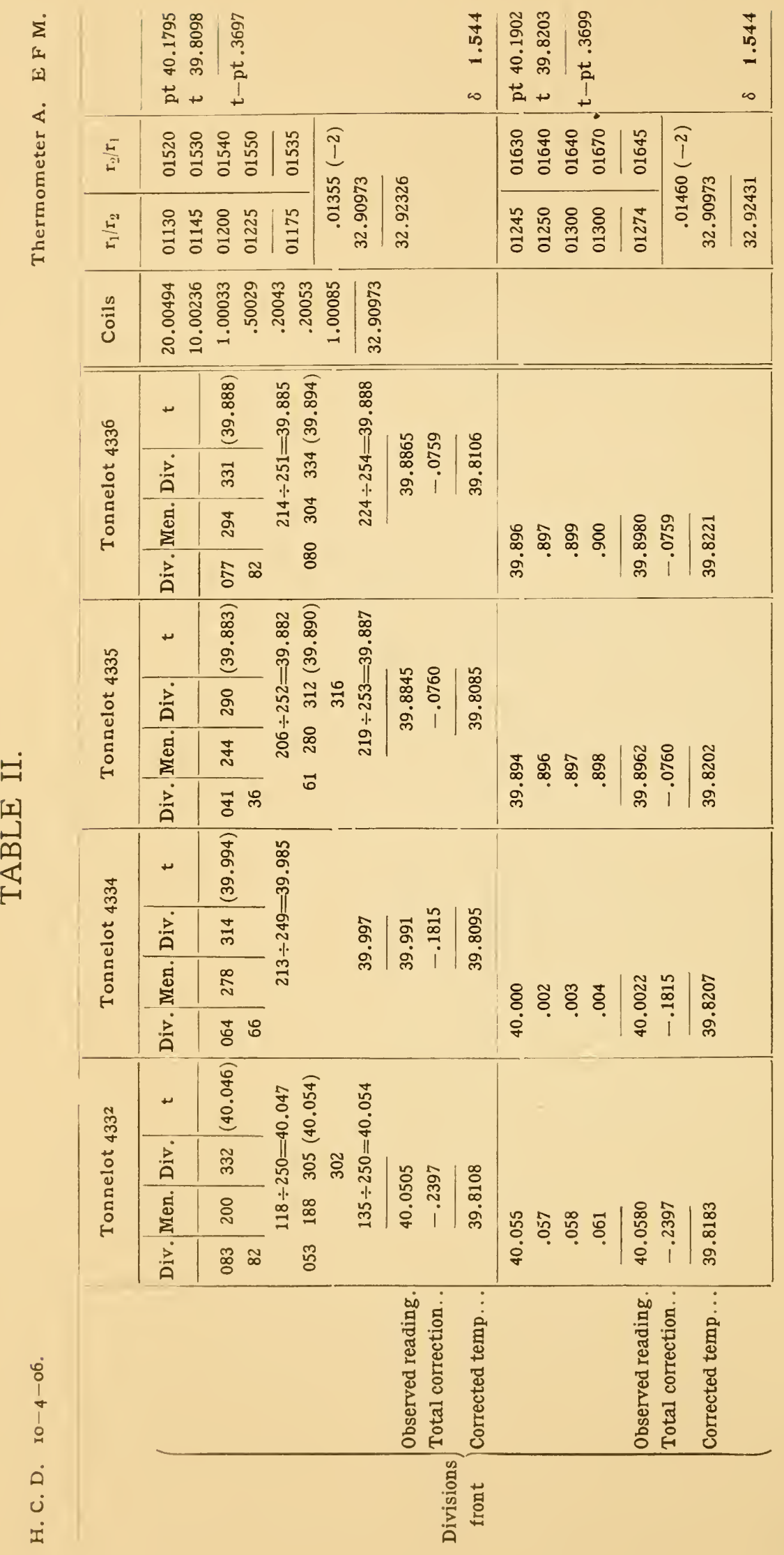




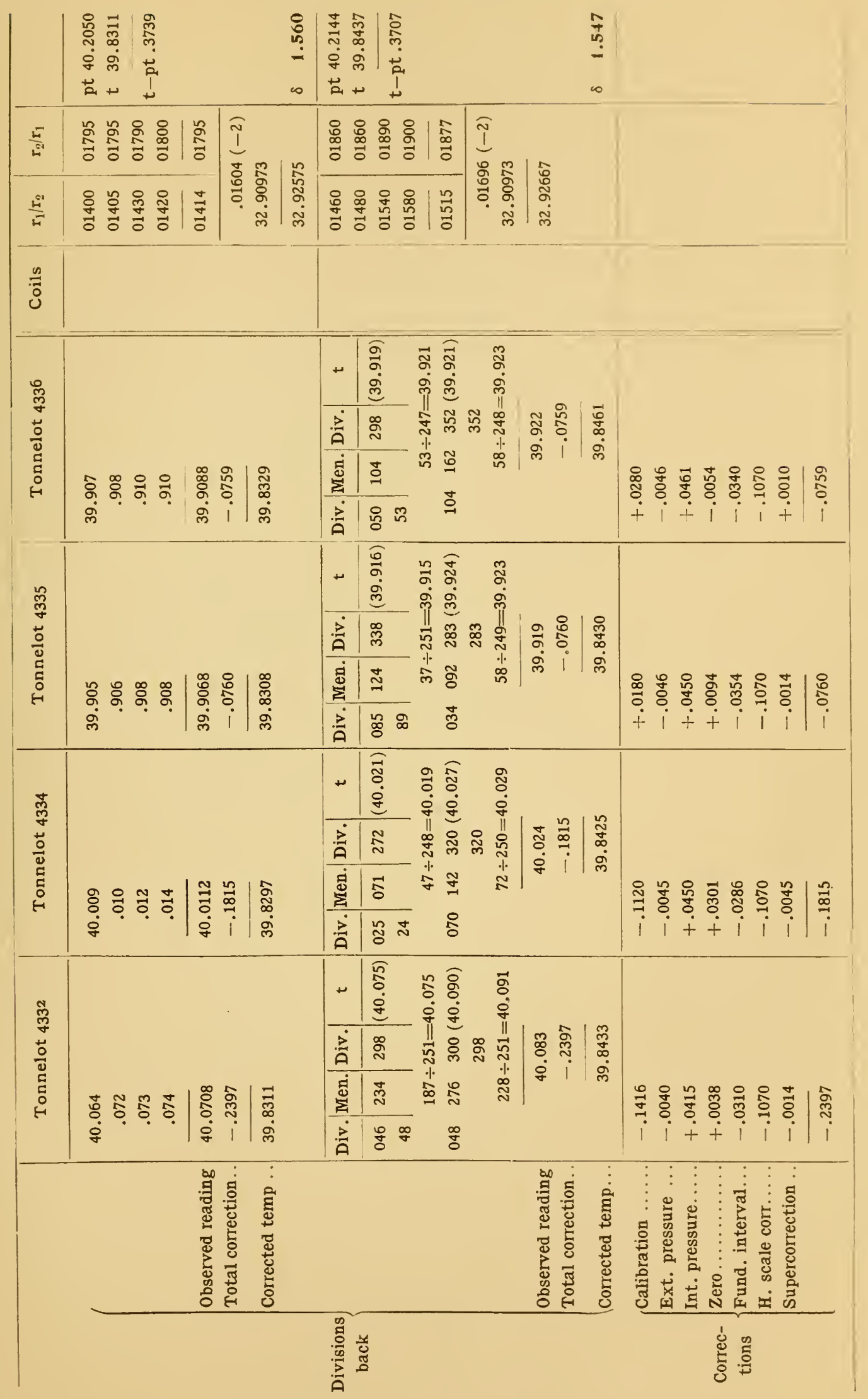




\section{TABLE III.}

Values of $\delta$.

\begin{tabular}{|c|c|c|c|c|c|c|c|c|c|}
\hline \multicolumn{5}{|c|}{ Thermometer A } & \multicolumn{5}{|c|}{ Thermometer B } \\
\hline Point & $t-p t$ & $\delta$ & $\begin{array}{c}\text { Observed } \\
\text { minus } \\
\text { mean }\end{array}$ & $\begin{array}{c}\text { Residual } \\
\text { in temp. } \\
\text { C }\end{array}$ & Point & $\mathrm{t}-\mathrm{pt}$ & $\delta$ & $\begin{array}{c}\text { Observed } \\
\text { minus } \\
\text { mean }\end{array}$ & $\begin{array}{l}\text { Residual } \\
\text { in temp. } \\
\text { C }\end{array}$ \\
\hline $30^{\circ}$ & .3264 & 1.560 & +.006 & $0 . .0013$ & $30^{\circ}$ & .3276 & 1.565 & +.009 & 09.0019 \\
\hline $40^{\circ}$ & .3711 & 1.548 & -.006 & .0014 & $40^{\circ}$ & .3707 & 1.547 & -.009 & .0021 \\
\hline $50^{\circ}$ & .3890 & 1.556 & +.002 & .0005 & $50^{\circ}$ & .3897 & 1.559 & +.003 & .0008 \\
\hline $60^{\circ}$ & .3722 & 1.550 & -.004 & .0010 & $60^{\circ}$ & .3742 & 1.558 & +.002 & .0005 \\
\hline \multirow[t]{2}{*}{$70^{\circ}$} & .3269 & 1.554 & .000 & .0000 & $70^{\circ}$ & .3259 & 1.550 & -.006 & .0013 \\
\hline & Mean & 1.554 & .004 & $0 \% 0008$ & & Mean & 1.556 & .006 & 0.0013 \\
\hline
\end{tabular}




\section{THE TRANSITION TEMPERATURE OF SODIUM SULPHATE.}

\section{INTRODUCTORY.}

Since it has been shown that the relation between platınum temperature and the International Hydrogen Scale in the interval $O^{\circ}$ to $100^{\circ}$ may be given by a single constant $(\delta)$ it is evident that this constant might be equally well determined at a single temperature (in addition to the two fixed points) if the determination were made with sufficient accuracy. The work of Richards ${ }^{8}$ and of Richards and Wells ${ }^{9}$ has shown that the transition point of sodium sulphate serves to fix a definite temperature which would be suitable for such determinations. Crystals of $\mathrm{Na}_{2} \mathrm{SO}_{4}$. IO $\mathrm{H}_{2} \mathrm{O}$ melt at about $32^{\circ} \cdot 4$. The presence of the anhydrous salt $\mathrm{Na}_{2} \mathrm{SO}_{4}$ apparently does not affect the equilibrium other than by taking up any water in excess of the water of crystallization. In other words, the phases $\mathrm{Na}_{2} \mathrm{SO}_{4}+$ $\mathrm{Na}_{2} \mathrm{SO}_{4}$. IO $\mathrm{H}_{2} \mathrm{O}+$ water + vapor are in equilibrium at a temperature which has been determined by a number of observers as being very near $32: 38$.

The very careful work of Richards and Wells and the small probable error deduced by them from their observations require that anyone attempting to repeat their work should have exceptional facilities for obtaining accurate results. On the other hand, it is very desirable to secure a further check on a point so important, in view of its proposed use in the calibration of calorimetric thermometers.

It was decided to use the two platinum thermometers, calibrated as above described, in a redetermination of this temperature. While this is an indirect method, it has certain advantages over a direct determination with mercurial thermometers. In the first place, the

${ }^{8}$ Am. J. Sci. 6, p. 20I; isgS.

${ }^{9}$ Proc. Am. Acad. of Arts and Sciences :3S, p. 431 ; 1902. 
platinum temperature could be determined to about 0 :oor by a single observation so that the errors in referring the point to the platinum scale become almost negligible and the whole problem is reduced to the relation between the platinum scale and the hydrogen scale, i. e., the accuracy of mercurial thermometers.

Since the four thermometers used at each point have not only been calibrated at the International Burean, but have been compared with a number of other primary standards ${ }^{10}$ also calibrated there and some of them directly compared with the standards of the International Bureau, they offer a means of reproducing the international hydrogen scale with the highest accuracy.

Noreover, the mercurial thermometers were used under conditions most favorable to attaining accurate results, i. e., with total immersion, reading at principal calibration points where their indications are most reliable and reading with a rising meniscus. This avoids one of the largest sources of error in using mercurial thermometers, i. e., the determination of a fixed point. In addition, as has been shown, the hydrogen scale represented by these platinum thermometers was obtained from the mean of observations taken at $30^{\circ}, 40^{\circ}$, $50^{\circ}, 60^{\circ}$, and $70^{\circ}$, so that in fact the determination of the transition temperature $32^{\circ} \cdot 38$ rests upon observations of four thermometers at each of five points.

\section{METHOD OF EXPERIMENT.}

The arrangement of the apparatus is shown in the accompanying figure, Fig. 4. $(B)$ is a cylindrical brass case $6 \mathrm{~cm}$ in diameter and $24 \mathrm{~cm}$ long, which was immersed to the point $(D)$ in a water bath ordinarily used for testing clinical thermometers. By this means the external temperature was regulated and could be maintained constant to 0 . I for any length of time. The salt was contained in a strong test tube $(N) 3 \mathrm{~cm}$ in diameter and $\mathrm{I}_{5} \mathrm{~cm}$ long holding about IoO grams. Smaller tubes holding about 50 grams were also used in some of the preliminary work. The head of the thermometer $(T)$ was held in place by a cork $(C)$ fitted into a removable sleeve $(S)$. The salt was thins entirely enclosed in an air space at the temperature of the surrounding water.

${ }^{10}$ Loc. cit., note 5 . 
The first experiments were made on a sample of "Kahlbaum" sodium sulphate. Following the procedure of Richards, the crystals were first broken up rather fine in a mortar, then melted in the test tube by dipping in warm water until the mass conld be readily stirred. The tube was then placed in position, the thermometer inserted, and readings taken at intervals during several hours. These observations showed that no very definite equilibrium had been established. Stirring the contents of the tube and small changes in the external temperature produced changes amounting to over 0 :or even after two hours. The procedure was therefore slightly modified, as follows: As the crystals seemed rather moist, a small quantity of the anhydrous salt was first added and the crystals were almost entirely melted. Recrystallization was then started by running cold water over the tube. In this way a perfectly definite temperature was secured within five minutes after starting the experiment. It was found later that the addition of anhydrous salt was unnecessary, as enough was formed during the process of preparing and melting. The procedure just indicated was followed in all subsequent experiments.

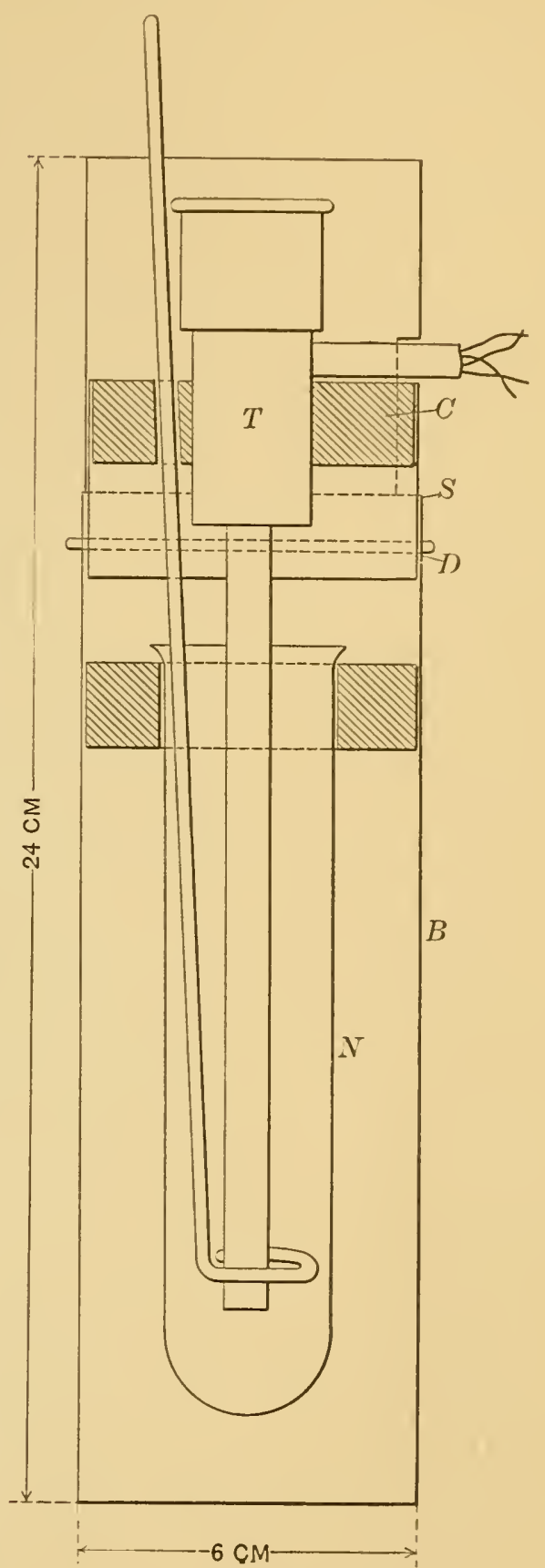

Fig. 4.

\section{THE EFFECT OF EXTERNAL CONDITIONS.}

In one experiment the external temperature was kept at $33^{\circ}$ for an hour and the temperature of the salt was observed at intervals. 
These observations showed variations of about $0: 0005$. The temperature was then dropped to $32^{\circ}$ for an hour, but no larger variations were observed. When the temperature was dropped to $23^{\circ}$ and maintained for about forty-five minutes, until the salt could no longer be stirred, no changes exceeding 0 :oo I were observed in the transition temperature. On raising the external temperature to $43^{\circ}$ a rise of about $0: 003$ was observed after thirty minutes, but it was noted that the salt was almost completely melted. The temperature was again lowered to $33^{\circ}$ and the original value was found. The experiment of lowering the temperature was tried a number of times with the same result. Richards found that lowering the outside temperature two or three degrees lowers the temiperature of the salt by about 0 .or. It seems probable that the procedure followed in the present instance, whereby new crystals are formed by sudden cooling, makes the transition temperature more definite and less dependent on external temperature. In this connection it should be pointed out that when the cooling was omitted the variations were not larger than the accidental errors of mercurial thermometers. These irregular observations, moreover, fell on both sides of the final value.

To test further the influence of externa conditions a smaller test tube was used. The salt was first melted in a large tube and the temperature observed; some of it was then transferred to the smaller tube, where the same value was again found. This experiment further indicates that the effects of superheating, conduction down the thermoneter stem, etc., were negligible. When the smaller tube was used, however, the external temperature had to be more carefully regulated, as a difference of 5 degrees from the transition point, if maintained for some time, began to affect the readings. Stirring the salt usually produced a small rise of less than 0.001 , which disappeared in two or three minutes.

\section{IMPURITIES.}

It seemed desirable to determine directly the error which might be introduced by the presence of impurities in the salt. Since the transition temperature must be determined with a mixture of crystals and solution, and the effect of the impurity except in some special cases, varies with the relative amount of the two present, it 
is evident that this effect will not remain constant. The values quoted in the table below are therefore only approximate, but serve to show what effect and range of variation may be expected in the transition temperature.

TABLE IV.

Effect of impurities.

\begin{tabular}{|c|c|c|c|c|c|c|}
\hline & \multicolumn{6}{|c|}{ Lowering of transition point for the following impurities- } \\
\hline & $0.2 \% \mathrm{NaCl}$ & $0.08 \% 6 \mathrm{NaCl}$ & $0.05 \% \mathrm{NaCl}$ & $0.01 \% \mathrm{NaCl}$ & $0.1 \% \mathrm{~K}_{2} \mathrm{SO}_{4}$ & $\left(\mathrm{~N} \mathrm{H}_{4}\right)_{2}^{0.1 \%} \mathrm{SO}_{4}$ \\
\hline & $0 ? 1885$ & $0 ! 0873$ & $0: 0505$ & $0: 0147$ & $0: 0620$ & $0: 0937$ \\
\hline & $0: 1942$ & $0 @ 1019$ & $0: 0486$ & $0: 0147$ & $0: 0607$ & 0.0922 \\
\hline & $0: 1942$ & $0: 1019$ & $0: 0490 ?$ & 0.0147 & & $0: 0911$ \\
\hline Mean & $0: 193$ & $0: 100$ & $0: 049$ & 0.015 & $0: 061$ & $0: 092$ \\
\hline
\end{tabular}

From the preliminary determinations it may be concluded (a) the transition temperature of sodium sulphate is definite to o:oor; (b) within a considerable range the transition temperature is not affected by external conditions (temperature and pressure); (c) the presence of $0.00 \mathrm{I}$ per cent of other salts may lower the transition temperature by 0 :oor. From the latter consideration it appears that if samples made by different methods give different values the higher is to be chosen as representing the purer salt.

\section{FINAL DETERMINATION.}

For the final determination four samples prepared by the chemical division of the Bureau of Standards, were used. No. I was prepared from Kahlbaum sodium sulphate three times recrystallized. No. 2 was the same salt five times recrystallized. No. 3 was prepared by nettralizing the carbonate and four times recrystallized. No. 4, was the same, five times recrystallized. Table $V$ shows values obtained for the different samples with the two thermometers.

The agreement of the two thermometers and the constancy of the values for each sample taken at different times show that the differences observed represent real differences in the transition temperature for the different samples. There is reason to believe that 
sample No. 2, which gives a low value, had been accidentally contaminated with some of the solution used in cleaning the tubes. It may be noted that the constancy of the indications for the various samples with varying conditions is not necessarily a proof of their purity, since any impurities which were not removed by recrystallization would have an effect independent of the relative amount of crystals and solution present. Samples prepared from the carbon-

TABLE V.

\begin{tabular}{|c|c|c|c|c|c|c|c|}
\hline Date & Therm. & Temp. & Mean & Date & Therm. & Temp. & Mean \\
\hline \multicolumn{3}{|c|}{ "Kahlbaum" } & & \multicolumn{3}{|c|}{ No. I } & \multirow[b]{3}{*}{$32 \circ 384$} \\
\hline \multirow[t]{2}{*}{$1-4-07$} & $A$ & $32: 3812$ & & $1-12-07$ & A & $32: 3832$ & \\
\hline & & & & & B & .3841 & \\
\hline \multirow[t]{2}{*}{$1-8-07$} & $A$ & $32: 3798$ & & \multicolumn{3}{|c|}{ No. III } & \multirow[b]{3}{*}{$32: 382$} \\
\hline & B & $: 3789$ & & $1-12-07$ & $A$ & $32: 3812$ & \\
\hline \multirow[t]{2}{*}{$3-7-07$} & A & $32: 3798$ & & & B & .3818 & \\
\hline & B & $: 3773$ & $32: 380$ & \multicolumn{3}{|c|}{ No. IV } & \\
\hline \multicolumn{3}{|c|}{ No. II } & & \multirow[t]{2}{*}{$1-5-07$} & A & $32: 3855$ & \\
\hline \multirow[t]{2}{*}{$1-7-07$} & A & $32: 3798$ & & & B & $: 3860$ & I \\
\hline & B & $: 3796$ & & \multirow[t]{2}{*}{$1-8-07$} & $A$ & $32: 3855$ & \\
\hline \multirow[t]{2}{*}{$1-8-07$} & A & $32: 3819$ & & & B & .3834 & \\
\hline & B & .3813 & & \multirow[t]{2}{*}{$1-12-07$} & $A$ & $32: 3812$ & \\
\hline \multirow[t]{2}{*}{$1-12-07$} & A & $32: 3799$ & & & \multirow[t]{2}{*}{ B } & \multirow[t]{2}{*}{.3818} & $32: 384$ \\
\hline & $\mathrm{B}$ & $: 3806$ & $32: 381$ & . & & & $32: 383$ \\
\hline
\end{tabular}

ate are less likely to contain impurities of this kind. Since differences between different samples are probably due to impurities which lower the transition temperature, the higher values may be taken as more nearly representing pure salt. The mean value from samples Nos. I, 3, and 4 is $32: 383^{11}$ But, for the reasons given above, the higher values are entitled to greater weight so that the most probable value from these observations is $32^{\circ} \cdot 3^{8} 4$.

${ }^{11}$ This value was found by Richards and Wells. 


\section{CONCLUSION.}

A special form of resistance thermometer, intended for calorimetric work, has been found applicable for general temperature measurement in the interval $0^{\circ}$ to IOO $^{\circ}$. Two of these thermometers have been compared with eight primary standard mercurial thermometers, representing the mean temperature scale of the Bureau of Standards, at the temperatures $30^{\circ}, 40^{\circ}, 50^{\circ}, 60^{\circ}$, and $70^{\circ}$. This calibration has shown that the Callendar formula $t-p t=$ $\delta(t /$ IOO - I $) t /$ Ioo may be used to define the relation between the platinum scale of these resistance thermometers and the mean scale of the Bureau of Standards to within 0.002. By using these calibrated thermometers the transition temperature of sodium sulphate has been determined and found to be 32.384 for the purest salt. Resistance thermometers for use in the interval $\mathrm{O}^{\circ}$ to $\mathrm{IOO}^{\circ}$ may be calibrated to the highest degree of accuracy by using the Callendar formula and determining the constant $\delta$ from the transition temperature of pure sodium sulphate, $3^{2} \cdot 384$. These thermometers may be used to reproduce the international hydrogen scale of temperature to within 0.002 or 0 .003.

In conclusion, the authors wish to express their obligations to Dr. C. W. Waidner for many valuable suggestions throughout the course of the present investigation, to Dr. F. A. Wolff, for a very careful calibration of the resistance bridge, and to Dr. Helen Ishain, who prepared the samples of sodium sulphate used in determinations of the transition temperature.

Washington, June 2 I, I907. 